\section{$\checkmark$ Georgia Ethics Committee Consortium: A Statewide Dialogue}

\section{KATHY KINLAW}

The Georgia Ethics Committee Consortium (GECC) is a statewide network of approximately 100 healthcare institutions including hospitals, health systems, hospices, home health agencies, long-term care facilities, and rehabilitation centers. The Consortium seeks to benefit healthcare recipients, care givers, and institutions by supporting existing institutional ethics committees and encouraging the development of such forums where they do not exist. The Emory University Center for Ethics in Public Policy and the Professions is the founding organization and host for the Consortium.

Respect for diversity of values and the uniqueness of individual communities that GECC supports, recognition of the centrality of the healthcare recipient to the ethics dialogue, and an acknowledgment of the importance of moral reasoning and imagination in medical decision making are foundational values for the Consortium. Throughout Georgia GECC supports education of and dialogue with patients and residents in healthcare institutions, their families, ethics committee members, healthcare providers, and civic, business, and policy leaders.

The Consortium formally began inviting members in January of 1994, but its founding was based on a dialogue with representatives of Georgia healthcare institutions during the 3 previous years. In August 1990 the Georgia Humanities Council awarded a 1-year grant to Kathy Kinlaw, Associate Director of the Emory Ethics Center, and Dr. Nicholas Fotion, Professor of Philosophy at Emory, to lead ethics seminars in hospitals throughout the state. At the conclusion of the grant period a statewide conference on healthcare ethics was cosponsored with the Georgia Hospital Association. The concept of developing a statewide network was introduced at this symposium. Three regional planning meetings in the summer of 1992 involving 75 representatives from healthcare institutions throughout the state confirmed the interest in moving forward with the Consortium. A survey was distributed to healthcare institutions early in 1993 to further determine how a statewide ethics network could support institutional and community interest in ethics.

In June 1993 a consortium planning group, which was geographically diverse and represented the variety of healthcare organizations in the state, was invited to meet at Emory. This group of 30 individuals representing 24 founding institutions met on a bimonthly basis and began inviting other consortium members in 1994.

Consortium member institutions appoint three voting representatives to the Consortium and educational programs are open to all staff at member institu- 
tions. Each year the Consortium hosts three meetings in each of three regions in the state and one statewide meeting. During the regional meetings a 2-hour educational presentation and discussion is offered followed by a business meeting for voting representatives only. The business meetings allow the opportunity for appointed representatives in each region to meet and to discuss current ethical issues in their organizations and communities and strategies for addressing them.

Topics addressed at regional meetings have included Ethical Implications of Man" aged Care, Organizational Ethics and the New JCAHO Standards, The Relationship Between Law and Ethics, Religious and Cultural Pluralism in Bioethics, and Redefining Autonomy. The statewide conference held in May 1995 was entitled Health Care in Transition: The Evolving Role of Ethics Committees.

The Consortium publishes a newsletter quarterly and assists in sharing institutional resources such as policies, case studies, and educational announcements. GECC maintains a video library for member institutions; serves as a resource for member institutions around educational, policy, and case concerns; and supports members in implementing Joint Commission standards regarding organizational ethics and patient rights.

The Consortium provides a structure for analysis of ethical issues of common interest to member institutions and others involved with health policy or healthcare delivery in the state. For example, the Consortium has formed a task force to consider the questions around assessment of futility and the implications for healthcare institutions weighing whether policies or procedures regarding futility should be developed at their institutions. Rather than serving as an advocacy group for particular policy positions, GECC acts as an educational resource for legislators and other policymakers. With the resources of the Emory Ethics Center the Consortium participates in research regarding the status of clinical ethics activity in the state.

The Consortium continues to be staffed by the Emory Ethics Center. In June 1994 additional monies were awarded by the Georgia Humanities Council that allowed the hiring of a part-time Program Director, Lane Busby McLelland, who works with Kathy Kinlaw in coordinating GECC.

Nationally recognized ethicists have been invited to assist in the development of the Consortium and the continued education of its members. The Consortium benefits from the experience of other ethics networks and hopes to strengthen the sharing of information between ethics committee networks.

The work of the Georgia Ethics Committee Consortium in affiliation with the Emory Ethics Center illustrates the rich potential for learning that exists among communities and in the juncture between theory and practice. 